\title{
Nonlinear impact of supply chain finance on the performance of seafood firms: A case study from
} Vietnam

\author{
Thu-Trang Thi Doan a and Toan Ngoc Bui ${ }^{a^{*}}$
}

${ }^{a}$ Faculty of Finance and Banking, Industrial University of Ho Chi Minh City (IUH), Vietnam

\begin{tabular}{l}
\hline C H R O N I C L E \\
\hline Article history: \\
Received October 25, 2019 \\
Received in revised format \\
December 26, 2019 \\
Accepted January 62020 \\
Available online \\
January 62020 \\
\hline Keywords: \\
GMM \\
Nonlinear \\
Performance \\
Supply chain finance \\
Vietnam
\end{tabular}

\section{Introduction}

International integration considerably boosts the import and export of seafood businesses in Vietnam. However, this force also brings them a number of challenges in management which creates a demand to adjust their operation and competitive ability. When facing these challenges, the management of supply chain in general and supply chain finance in particular is a major issue to be paid more attention. In fact, Vietnam has just experienced many predicaments caused by the global financial crisis, so it is not easy to access to credit institutions as well as stock market. Therefore, seafood firms frequently aim to the improvement in supply chain finance in order to optimize their working capital. More than that, supply chain finance helps lower capital cost (Wuttke et al., 2013), and more specially improves firm performance (Raghavan \& Mishra, 2011; Lekkakos \& Serrano, 2016). Despite its importance in boosting how the firm performs, this topic has not been common in empirical research. Only few scholars, namely, Zhang et al. (2019) and Bui (2020b) have investigated the impact of supply chain

* Corresponding author

E-mail address: buingoctoan@iuh.edu.vn (T.N. Bui)

(C) 2020 by the authors; licensee Growing Science. doi: $10.5267 /$ j.uscm.2020.1.001

\begin{abstract}
Supply chain finance has become an interesting research topic which attracts lots of attention from scholars recently, particularly after the global financial crisis. However, only few studies More specially, there is a big research gap when almost none of existing research has analysed the nonlinear impact of supply chain finance on firm performance. With this aim, this paper succeeds in giving first empirical evidence on the U-shaped nonlinear relationship between supply chain finance and the performance of seafood firms in Vietnam. Specifically, a bad lower firm performance (FP). Nevertheless, if any decrease in firm performance reaches its minimum $\left(\mathrm{CCC}^{*}\right)$, the restructuring of the firm will gradually improve it. In addition, firm performance is significantly influenced by controlled variables of firm-specific, firm size findings and capital structure (CAP), and macroeconomic, economic growth (EG), factors. The perspective on the causal relationship between supply chain finance and firm performance.
\end{abstract}

(C) 2020 by the authors; license Growing Science, Canada. 
finance on firm performance. Interestingly, all these studies report that supply chain finance helps raise the performance of its participants. However, is supply chain finance always positively correlated to the firm performance? Does the optimal threshold really exist in this correlation? This is a big research gap which needs to be filled for the answers. Accordingly, this study is conducted with the aim of providing first empirical evidence on the causal correlation between supply chain finance and seafood firm performance in Vietnam.

\section{Literature review}

The performance of supply chain finance is usually measured by indicator of cash conversion cycle (Zhang et al., 2019), which is defined as the period starting from the cash outlay to cash recovery (Zhang et al., 2019; Bui, 2020b). According to Wuttke et al. (2013), the decrease in cash conversion cycle makes firms speed up the cash conversion by a lower cost of capital. Also, this indicates a robust financial connection in the supply chain (Wuttke et al., 2013), so its participants perform better. Contrariwise, a bad performance of supply chain finance brings its participants difficulties in raising their trade credit form suppliers and stabilizing supply chain which exert big influence on their performance. It can be stated that supply chain finance plays a vital role in the optimization of financial flows (Pfohl \& Gomm, 2009), and working capital (Liebl et al., 2016); the stabilization of the entire supply chain (Klapper, 2006); and more particularly the increase in firm performance (Raghavan \& Mishra, 2011; Lekkakos \& Serrano, 2016). Although supply chain finance has been analysed more since the beginning of twenty-first century (Pfohl \& Gomm, 2009), especially after the global financial crisis (Polak et al., 2012), the impact of supply chain finance on firm performance is only examined by few researchers, namely Zhang et al. (2019) and Bui (2020b) who intriguingly reveal their positive correlation. In other words, a short cash conversion cycle stimulates the supply chain participants to perform more effectively. Further, the performance is also influenced by some control variables of firm-specific and macroeconomic factors such as capital structure (Azhagaiah \& Gavoury, 2011; Malik, 2011; Akinlo \& Asaolu, 2012; González, 2013; Chechet \& Olayiwola, 2014; Vithessonthi \& Tongurai, 2015; Daud et al., 2016; Ameen \& Shahzadi, 2017; Ghayas \& Akhter, 2018; Bui, 2020b), firm size (Malik, 2011; Akinlo \& Asaolu, 2012; Vithessonthi \& Tongurai, 2015; Daud et al., 2016; Bui, 2020b), and economic growth (Vithessonthi \& Tongurai, 2015). Accordingly, a healthy economy and large size of the participants facilitate the improvement of their performance. Also, more loans (especially medium- and long-term ones) and their inefficient uses place more financial burdens on these firms and negatively influence their performance. Based on these, next, the author develops a model of the nonlinear impact of supply chain finance on the performance of Vietnam seafood firms.

\section{Data and methodology}

\subsection{Data collection}

The paper uses data from World Bank and financial statements of 20 seafood companies listed on Vietnam stock exchange. These data are collected from 2010 to 2018 when Vietnam seafood industry made a positive recovery after the global financial crisis.

\subsection{Methodology}

With the objective of examining the nonlinear impact of supply chain finance on the performance of Vietnam seafood firms, the author analyses the model by employing Pooled regression (POLS), Fixed effects model (FEM) and Random effects model (REM). Then, regression analysis is performed to address potential endogeneity, heteroskedasticity, and autocorrelation issues. Following that, Generalized Method of Moment (GMM) is adopted to repair problems in regression-based hypotheses

(if any) and potential endogeneity (Bui, 2020b; Doan, 2020a; Doan, 2020b). Specially for nonlinear impact model, the GMM is superior to other models (Bui, 2020a). Based on the earlier results, it can be seen that firm performance (FP) is measured by return on assets (ROA) while supply chain finance is measured by cash conversion cycle (CCC) defined as the period starting from the cash outlay to cash 
recovery. Additionally, squares of cash conversion cycle $\left(\mathrm{CCC}^{2}\right)$ is included in the paper to consider the nonlinear effect of supply chain finance on the performance of Vietnam seafood firms, which is its novelty. About control variables, firm size (logarithm of total assets - SIZE), capital structure (total debt to total assets - CAP), and economic growth (EG). Consequently, the following model is proposed:

$$
\mathrm{FP}_{i t}=\beta_{0}+\beta_{1} \mathrm{CCC}_{\mathrm{it}}+\beta_{2} \mathrm{CCC}^{2}{ }_{\mathrm{it}}+\beta_{3} \mathrm{SIZE}_{\mathrm{it}}+\beta_{4} \mathrm{CAP}_{\mathrm{it}}+\beta_{5} \mathrm{EG}_{\mathrm{t}}+\varepsilon_{\mathrm{it}}
$$

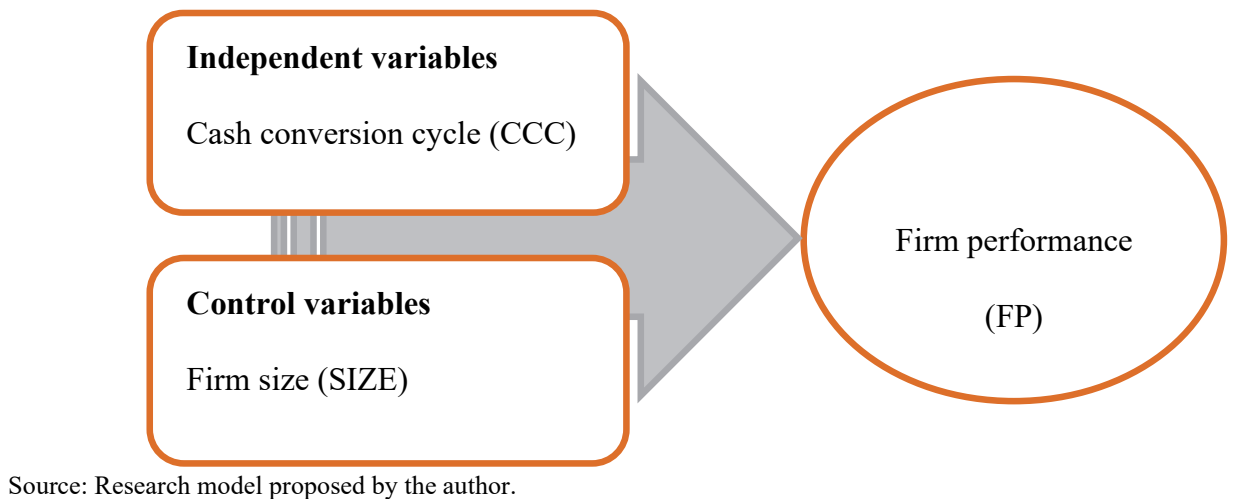

where:

Fig. 1. Proposed research model

Dependent variable: Firm performance (FP).

Independent variables: Cash conversion cycle (CCC), squares of cash conversion cycle $\left(\mathrm{CCC}^{2}\right)$. Control variables: Firm size (SIZE), capital structure (CAP), economic growth (EG).

\section{Empirical results}

Variable correlations are shown in Table 1 as follows,

\section{Table 1}

Variable correlations

\begin{tabular}{cccccc}
\hline & FP & CCC & SIZE & CAP & EG \\
\hline FP & 1.000 & & & & \\
CCC & -0.0864 & 1.000 & & & \\
SIZE & 0.2292 & -0.1700 & 1.000 & 1.000 & \\
CAP & -0.5223 & 0.3099 & -0.2331 & 0.0868 & 1.000 \\
EG & 0.0048 & 0.0534 & 0.0765 &
\end{tabular}

Source: Computed by the author.

Table 1 reveals that cash conversion cycle (CCC) and capital structure (CAP) are negatively correlated to firm performance (FP) while firm size (SIZE) and economic growth (EG) are positively associated with firm performance (FP). Results of analysis by Pooled Regression model (POLS), Fixed effects model (FEM), and Random effects model (REM) are shown in Table 2 as follows:

Table 2

Results of estimating research models using POLS, FEM, REM methods

\begin{tabular}{|c|c|c|c|}
\hline FP & POLS & FEM & REM \\
\hline Constant & -0.0558 & $-0.3456^{* * *}$ & $-0.1071^{*}$ \\
\hline $\mathrm{CCC}$ & 0.0001 & 0.0001 & $0.0001^{*}$ \\
\hline $\mathrm{CCC}^{2}$ & $-1.69 * 10^{-8}$ & $-1.99 * 10^{-9}$ & $-1.52^{*} 10^{-8}$ \\
\hline SIZE & $0.0049^{*}$ & $0.0294^{* * *}$ & $0.0092^{* *}$ \\
\hline CAP & $-0.0512^{* * *}$ & $-0.0499^{* * *}$ & $-0.0526^{* * *}$ \\
\hline EG & 0.4168 & -0.1347 & 0.3257 \\
\hline $\mathrm{R}^{2}$ & $29.95 \%$ & $32.34 \%$ & $28.63 \%$ \\
\hline Significance level & $\begin{array}{c}\mathrm{F}(5,174)=14.88 \\
\text { Prob }>\mathrm{F}=0.0000^{* * *}\end{array}$ & $\begin{array}{c}\mathrm{F}(5,155)=14.82 \\
\text { Prob }>\mathrm{F}=0.0000^{* * *}\end{array}$ & $\begin{array}{l}\text { Wald chi } 2(5)=69.29 \\
\text { Prob }>\operatorname{chi} 2=0.0000^{* * *}\end{array}$ \\
\hline $\mathrm{F}$ test & & $F(19,155)=2.93 \quad$ Prob $>F=0.0001^{* * *}$ & \\
\hline Hausman test & & $\operatorname{chi} 2(4)=15.73 \quad$ Prob $>$ chi $2=0.0034^{* * *}$ & \\
\hline
\end{tabular}


From Table 2, it can be seen that F-test is significant at the $1 \%$ level while Hausman test has the 1 percent level of significance. Therefore, it can be deduced that the result of the fixed effects model (FEM) shows its appropriateness.

Table 3

Results of tests on multicollinearity, heteroscedasticity and autocorrelation

\begin{tabular}{|c|c|c|c|}
\hline \multicolumn{2}{|c|}{ Multicollinearity test } & \multirow{2}{*}{ Heteroscedasticity test } & \multirow{2}{*}{ Autocorrelation test } \\
\hline Variable & VIF & & \\
\hline $\mathrm{CCC}$ & 4.47 & \multirow{6}{*}{$\begin{array}{l}\text { chi2 }(20)=19,884.48 \\
\text { Prob }>\text { chi } 2=0.000^{* * *}\end{array}$} & \multirow{6}{*}{$\begin{array}{c}F(1,19)=3.514 \\
\text { Prob }>F=0.0763^{*}\end{array}$} \\
\hline $\mathrm{CCC}^{2}$ & 5.16 & & \\
\hline SIZE & 1.09 & & \\
\hline CAP & 1.36 & & \\
\hline EG & 1.03 & & \\
\hline Mean V & & & \\
\hline
\end{tabular}

Table 3 reveals that there are no serious problems of multicollinearity. Meanwhile, heteroscedasticity and autocorrelation issues really exist. Accordingly, the GMM is chosen for investigating the nonlinear impact of supply chain finance on firm performance. The GMM is superior in controlling heteroscedasticity, autocorrelation and potential endogeneity issues (Doytch \& Uctum, 2011).

Table 4

Model estimation results by GMM method

\begin{tabular}{|c|c|}
\hline FP & Coef. \\
\hline Constant & $0.000^{* * *}$ \\
\hline $\mathrm{CCC}$ & $0.009^{* * *}$ \\
\hline $\mathrm{CCC}^{2}$ & $1.39 * 10^{-7}$ \\
\hline SIZE & $0.001^{* * *}$ \\
\hline CAP & -0.0358 \\
\hline EG & $\begin{array}{cc}1.2335 & 0.013^{* *}\end{array}$ \\
\hline Significance level & Wald $\operatorname{chi} 2(4)=101.42$ Prob $>$ chi $2=0.000^{* * *}$ \\
\hline Arellano-Bond test for AR(2) in first differences & $\mathrm{z}=1.35 \quad \operatorname{Pr}>\mathrm{z}=0.176$ \\
\hline Sargan test & $\operatorname{chi} 2(2)=1.76 \quad$ Prob $>\operatorname{chi} 2=0.416$ \\
\hline
\end{tabular}

Results of Sargan test indicate that instrumental variables adopted in the model is appropriate. Also, according to Arellano-Bond test's results, autocorrelation does not really exist (Table 4). It can be concluded that the results are valid. As can be seen from the results, firm performance (FP) is negatively influenced by CCC (-0.0002) and positively influenced by $\operatorname{CCC}^{2}\left(1.39 \times 10^{-7}\right)$ at the $1 \%$ level of significance. These are consistent with what Zhang et al. (2019) and Bui (2020b) who have reported the negative association between cash conversion cycle (CCC) and squares of cash conversion cycle $\left(\mathrm{CCC}^{2}\right)$ of firm performance (FP). Alternatively, the U-shaped nonlinear effect of supply chain finance on firm performance really exists, which is a novelty of this study. Thus, the low performance of supply chain finance (cash conversion cycle (CCC) increases) will lower firm performance (FP). However, when this decrease reaches its minimum $\left(\mathrm{CCC}^{*}\right)$, the firm will undergo restructuring for its recovery and improvement (Fig. 2). Accordingly, the initial research question will be explained as follows: the relationship between supply chain finance and firm performance is U-shaped nonlinear impact, i.e. supply chain finance does not always exert positive influence on how the firm performs. Concurrently, there is an optimal threshold for this impact, alternatively the minimum of CCC*. 


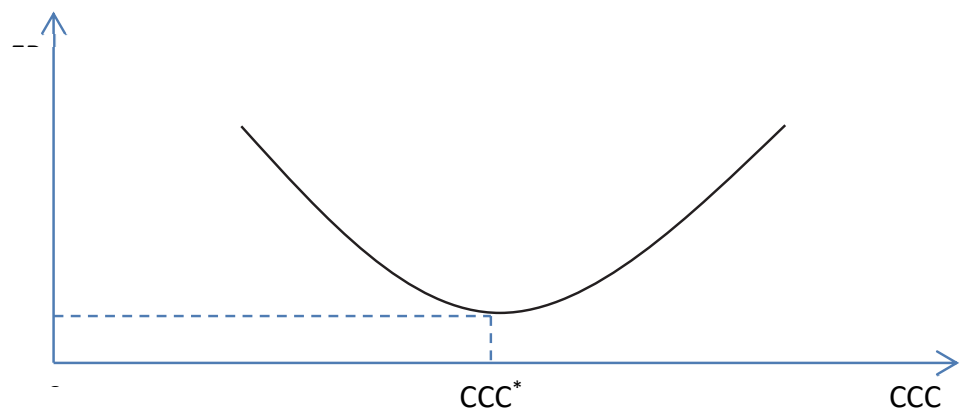

Source: Computed by the author.

Fig. 2. Nonlinear impact of supply chain finance on firm performance

Besides, firm performance (FP) is significantly correlated with the control variables of firm-specific and macroeconomic factors (namely economic growth (EG)). Specifically, firm size (SIZE) positively affects $(0.0130)$ firm performance (FP) at the $1 \%$ level of significance. This corroborates results of Malik (2011), Akinlo and Asaolu (2012), Vithessonthi and Tongurai (2015), Daud et al. (2016). Meanwhile, capital structure (CAP) is negatively (-0.0358) associated with how the firm performs at the $10 \%$ level of significance. This result is intriguingly what Azhagaiah and Gavoury (2011), Malik (2011), Akinlo and Asaolu (2012), González (2013), Chechet and Olayiwola (2014), Vithessonthi and Tongurai (2015), Daud et al. (2016), Ameen and Shahzadi (2017), Ghayas and Akhter (2018) have been found previously. Moreover, economic growth (EG) positively influences the performance (1.2335) at the significance level of 5 percent. This contributes to the result of Vithessonthi and Tongurai (2015).

\section{Conclusions}

The paper has succeeded in giving first empirical evidence on the nonlinear impact of supply chain finance on the firm performance. Particularly, the inefficiency of supply chain finance will cause a fall in the firm performance. Nevertheless, when this fall reaches its lowest threshold, restructure will be done in the firm in order to recover and improve its turnover. Thus, it can be deduced that supply chain finance exerts U-shaped nonlinear impact on the performance, so the optimal threshold in the impact can be defined by the minimum of $\mathrm{CCC}^{*}$. In addition, the paper reveals that firm performance is significantly related to firm-specific (firm size (SIZE) and capital structure (CAP)) and macroeconomic (economic growth (EG)) determinants. In short, supply chain finance does not frequently exert positive impact on how its participants perform. Their restructuring occurred by the lowest threshold (CCC $\left.{ }^{*}\right)$ makes this correlation considerably changes. This empirical evidence is essential in giving the management and scholars a comprehensive perspective on the nexus between supply chain finance and firm performance. However, due to short dataset, the author is not able to investigate this correlation employing cubic or quartic function for a longer observation on this nonlinear impact. This may be an interesting proposal for future research.

\section{References}

Akinlo, O., \& Asaolu, T. (2012). Profitability and Leverage: Evidence from Nigerian firms. Global journal of business research, 6(1), 17-25.

Ameen, A., \& Shahzadi, K. (2017). Impact of Capital Structure on Firms Profitability: Evidence from Cement Sector of Pakistan. Research Journal of Finance and Accounting, 8(7), 29-34.

Azhagaiah, R., \& Gavoury, C. (2011). The Impact of Capital Structure on Profitability with Special Reference to it Industry in India. Managing Global Transitions, 9(4), 371-392.

Bui, T.N. (2020a). Domestic credit and economic growth in Asean countries: A nonlinear approach. International Transaction Journal of Engineering, Management, \& Applied Sciences \& Technologies, 11(2), 1-9. 
Bui, T.N. (2020b). Supply chain finance, financial development and profitability of real estate firms in Vietnam. Uncertain Supply Chain Management, 8(1), 37-42.

Chechet, I.L., \& Olayiwola, A.B. (2014). Capital Structure and Profitability of Nigerian Quoted Firms: The Agency Cost Theory Perspective. American International Journal of Social Science, 3(1), 139158.

Daud, W.M.N.W., Norwani, N.M., Mansor, A.A., \& Endut, W.A. (2016). Does Financing Decision Influence Corporate Performance in Malaysia?. International Journal of Economics and Financial Issues, 6(3), 1165-1171.

Doan, T.T.T. (2020a). Profitability of real estate firms: Evidence using GMM estimation. Management Science Letters, 10(2), 327-332.

Doan, T.T.T. (2020b). Financing decision and firm performance: Evidence from an emerging country. Management Science Letters, 10(4), 849-854.

Doytch, N., \& Uctum, M. (2011). Does the worldwide shift of FDI from manufacturing to services accelerate economic growth? A GMM estimation study. Journal of International Money and Finance, 30(3), 410-427.

Ghayas, A., \& Akhter, J. (2018). Impact of Capital Structure on Profitability: An empirical analysis of listed firms in India. Asian Journal of Managerial Science, 7(2), 1-6.

González, V.M. (2013). Leverage and corporate performance: International evidence. International Review of Economics and Finance, 25, 169-184.

Klapper, L.F. (2006). The role of factoring for financing small and medium enterprises. Journal of Banking \& Finance, 30(11), 3111-3130.

Lekkakos, S.D., \& Serrano, A. (2016). Supply chain finance for small and medium sized enterprises: the case of reverse factoring. International Journal of Physical Distribution \& Logistics Management, 46(4), 367-392.

Liebl, J., Hartmann, E., \& Feisel, E. (2016). Reverse factoring in the supply chain: objectives, antecedents and implementation barriers. International Journal of Physical Distribution \& Logistics Management, 46(4), 393-413.

Malik, H. (2011). Determinants of Insurance Companies Profitability: an Analysis of Insurance Sector of Pakistan. Academic Research International, 1(3), 315-321.

Pfohl, H.C., \& Gomm, M. (2009). Supply chain finance: optimizing financial flows in supply chains. Logistics Research, 1(3), 149-161.

Polak, P., Sirpal, R., \& Hamdan, M. (2012). Post-crisis emerging role of the treasurer. European Journal of Scientific Research, 86(3), 319-339.

Raghavan, N.S., \& Mishra, V.K. (2011). Short-term financing in a cash-constrained supply chain. International Journal of Production Economics, 134(2), 407-412.

Vithessonthi, C., \& Tongurai, J. (2015). The effect of leverage on performance: Domestically-oriented versus internationally-oriented firms. Research in International Business and Finance, 34, 265-280.

Wuttke, D.A., Blome, C., Foerstl, K., \& Henke, M. (2013). Managing the innovation adoption of supply chain finance - empirical evidence from six European case studies. Journal of Business Logistics, 34(2), 148-166.

Zhang, T., Zhang, C.Y., \& Pei, Q. (2019). Misconception of Providing Supply Chain Finance: Its Stabilising Role. International Journal of Production Economics, 213, 175-184.

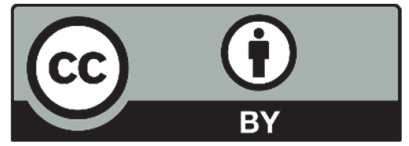

(C) 2020 by the authors; licensee Growing Science, Canada. This is an open access article distributed under the terms and conditions of the Creative Commons Attribution (CC-BY) license (http://creativecommons.org/licenses/by/4.0/). 